Article

\title{
An Analysis of the Work Resumption in China under the COVID-19 Epidemic Based on Night Time Lights Data
}

\author{
Suzheng Tian ${ }^{1,2}$, Ruyi Feng ${ }^{1,2}$, Ji Zhao ${ }^{1,2}$ and Lizhe Wang ${ }^{1,2, *(D)}$ \\ 1 School of Computer Science, China University of Geosciences, 388 Lumo Road, Wuhan 430074, China; \\ tiansuzheng@cug.edu.cn (S.T.); fengry@cug.edu.cn (R.F.); zhaoji@cug.edu.cn (J.Z.) \\ 2 Hubei Key Laboratory of Intelligent Geo-Information Processing, China University of Geosciences, \\ Wuhan 430074, China \\ * Correspondence: lizhe.wang@gmail.com
}

check for updates

Citation: Tian, S.; Feng, R.; Zhao, J.; Wang, L. An Analysis of the Work Resumption in China under the COVID-19 Epidemic Based on Night Time Lights Data. ISPRS Int. J. Geo-Inf. 2021, 10, 614. https://doi.org/ $10.3390 /$ ijgi10090614

Academic Editor: Wolfgang Kainz

Received: 31 May 2021

Accepted: 13 September 2021

Published: 15 September 2021

Publisher's Note: MDPI stays neutral with regard to jurisdictional claims in published maps and institutional affiliations.

Copyright: (c) 2021 by the authors. Licensee MDPI, Basel, Switzerland. This article is an open access article distributed under the terms and conditions of the Creative Commons Attribution (CC BY) license (https:/ / creativecommons.org/licenses/by/ $4.0 /)$.

\begin{abstract}
Public emergencies often have an impact on the production and operation of enterprises Timely and effective quantitative measurement of enterprises' offline resumption of work after public emergencies is conducive to the formulation and implementation of relevant policies. In this study, we analyze the level of work resumption after the coronavirus disease 2019 (COVID-19)-influenced Chinese Spring Festival in 2020 with night time lights remote sensing data and Baidu Migration data. The results are verified by official statistics and facts, which demonstrates that COVID-19 has seriously affected the resumption of work after the Spring Festival holiday. Since 10 February, work has been resuming in localities. By the end of March, the work resumption index of most cities exceeded 70\% and even Shanghai, Nanjing and Suzhou had achieved complete resumption of work. Wuhan only started to resume work in the last week of March due to the more severe outbreak. Although the level of work resumption is gradually increasing in every area, the specific situation of resumption of work varies in different regions. The process of work resumption in coastal areas is faster, while the process is relatively slow in inland cities.
\end{abstract}

Keywords: night time lights; the resumption of work; COVID-19; remote sensing; Baidu Migration

\section{Introduction}

In December 2019, COVID-19 outbroke in Wuhan, China [1,2]. The epidemic spread across the whole country with the virus's highly infectious and mass migration movements before the Spring Festival of China. To contain the outbreak, Wuhan went into lockdown and the other regions curbed population flow since 23 January 2020 [3]. Everyone must make fewer trips outside and the Chinese New Year holiday was extended. The COVID-19 outbreak has seriously affected all aspects of society and China's economic activities have been stagnant for a short period [4]. Since the prevention work was carried out strictly, the epidemic situation has witnessed positive changes. Work has been resuming in an orderly manner in many regions for economic development since 10 February. Due to the various difficulties and risks in the process, it takes a long time to recover completely. Therefore, dynamic monitoring of the resumption of work is urgently needed. An accurate understanding of the level of resumption of work can provide necessary quantitative support for steadily promoting the formulation and implementation of relevant policies for enterprises' resumption of work and production.

The studies of resumption of work mostly focus on the individual, with emphasis on the factors influencing individual return to work after injury or illness $[5,6]$. For the measurement of the resumption of work in this epidemic, it is generally the statistical data collected by the Bureau of Statistics, industry associations and other organizations. Since February 2020, the government has gradually announced the rate of work resumption of enterprises above designated size (here, the enterprise is denoted as the revenue of major business above 2000 million yuan) on the province scale. However, manual statistics are a 
costly and cumbersome undertaking and the results exhibit hysteresis. Enterprises above the designated size do not represent small and medium-sized enterprises. Therefore, a method is urgently needed to estimate the rework rate.

Scholars tried to use different quantitative methods to study the resumption of work in public emergencies. Nie et al. [7] used 931 sample data of mobile terminal locations to calculate the resumption level of enterprises. However, the sample data is not representative of the entire region. Gan et al. [8] used the migration index to calculate the intensity of the resumption of work in cities and proved that the level of work resumption was significantly related to the shortage of manpower, the number of basic regenerations and GDP. Xu et al. [9] used big data from Baidu Migration to analyse the level of social production and life recovery after the Spring Festival affected by COVID-19 in 2020. Li et al. [10] calculated the work resumption rate for 366 cities in China in 2020 based on Baidu's migration-in and migration-out data and predicted the average monthly income of migrant workers under different scenarios. However, they only estimated the level of resumption of work in February as a whole or on a date and did not get a long-term change in the resumption of work. So far, there are still few studies on the dynamic measurement of enterprises' resumption of work by provinces and cities in the academic circle.

Remote sensing data becomes an important data source with unique timeliness and availability owing to the rapid development of remote sensing technology. It is widely used in the study of natural disasters and epidemic diseases [11,12]. Remote sensing data of night light emissions can be used to monitor the intensity of human activities by detecting the urban night time lights (NTLs), even the low-intensity night light generated by the small-scale residential area, traffic flow, etc. $[13,14]$. Therefore, NTLs data is widely used in many research fields such as urban development research [15-20], socio-economic parameter estimation [21-24], major events assessment [25,26], fishery monitoring [27,28], holidays in lights [29], mapping fires, gas flares and greenhouse gas emissions [30-33] and so on. Similarly, NTLs data were applied to the impact of the COVID-19 outbreak on society $[34,35]$. In studies of major events assessment based on NTLs, scholars mostly focus on the restoration of electric power and economic losses [36-39], with little attention to the resumption of work. Though the COVID-19 epidemic, unlike natural disasters, did not result in damage to electrical utilities, the decrease in the brightness of the night time light is still noticeable due to the shutdown of almost all industries. Liu et al. [40] used night time light and air quality data to analyze the COVID-19 impacts on human activities and the environment. They found that the lights in residential areas increased, while the brightness of commercial centers decreased significantly during the epidemic period. Elvidge et al. [41] also demonstrated light dimming in China using different reference images, epidemiological images, scatter plots and night time profiles during the COVID-19 Pandemic. However, previous studies have shown that night time lights in China have been growing for several decades [42]. As shown in Figure 1, the luminous intensity of Beijing decreases in February and increases in March using National Polar-orbiting Partnership Visible Infrared Imaging Radiometer Suite (NPP-VIIRS) Day/Night Band (DNB) monthly average radiance composite night time lights data. It means that the brightness of the NTLs decreased under the influence of the New Year holiday (Chinese New Year 2020 starts on 25 January) and the epidemic. In addition, with the resumption of work, the brightness of the lights may gradually recover. So, the NTLs can be used as a proxy indicator to monitor the recovery of the economic activity level. Lan et al. [43] used NPP-VIIRS DNB daily data to explore the impact of the epidemic and the extent of return to work in China. The high agreement between urban travel intensity and NTLs data proved the validity of the results. Yin et al. [44] used ratio maps, difference maps, wave indices and recovery rates based on night time lighting data to demonstrate the recovery patterns and spatial distribution characteristics of NTLs. However, none of them took into account that night time lighting in residential areas can affect the resumption rate. 


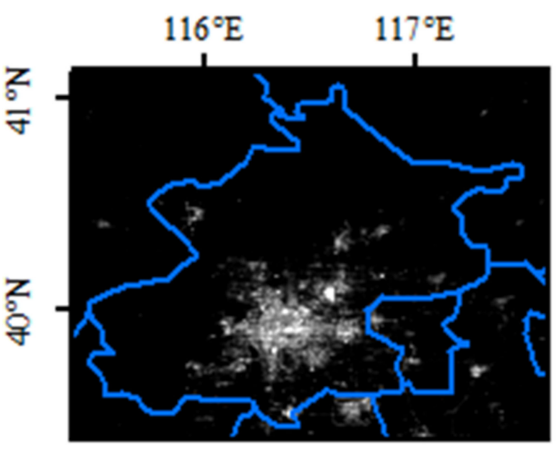

(a)March 2020

administrative boundary

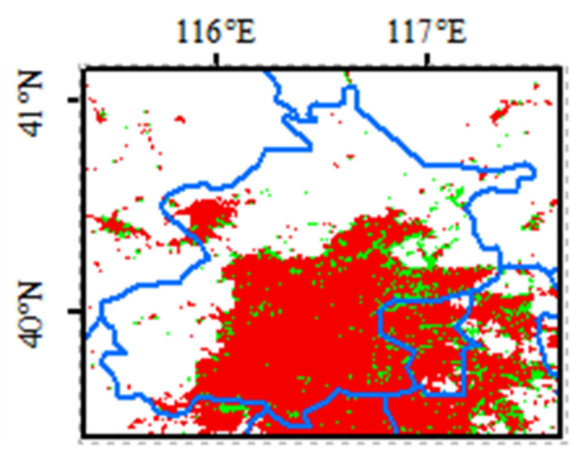

(b) January-February 2020 391.752

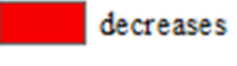

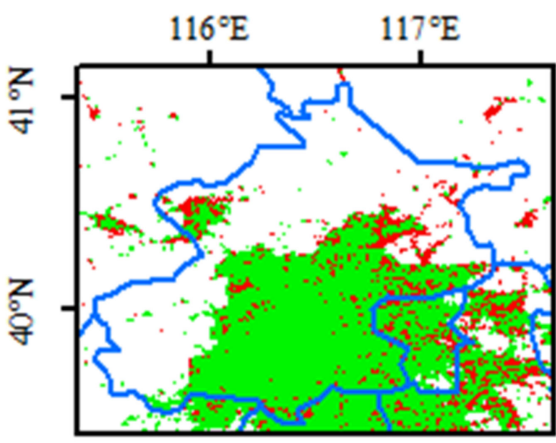

(c)February-March 2020

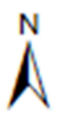

Figure 1. The change of NTLs in Beijing from January 2020 to March 2020. (a) VIIRS monthly composite NTLs image in March 2020 (unit: $\mathrm{nW} \cdot \mathrm{cm}^{-2} \cdot \mathrm{sr}^{-1}$ ). (b) Difference of VIIRS NTLs between February 2020 and January 2020. (c) Difference of VIIRS NTLs between March 2020 and February 2020.

It is unrealistic to count the work resumption rate of each area manually. The above study shows that night time lighting data and Baidu map migration data can be applied to the work resumption rate study. To estimate the resumption level as accurately as possible, NPP-VIIRS night time lights together with urban travel intensity (UTI) data from Baidu Map are utilized to calculate the work resumption index (the approximate offline work resumption rate) after the COVID-19-influenced Chinese Spring Festival. First, the NPP-VIIRS DNB night time lights data are calibrated to remove the influence of clouds, moonlight and other factors. Next, the VIIRS images are eliminated residential pixels using urban land use data. Then, the linear regression algorithm is used to calculate the trend of the time series of each pixel of NTLs images to fill in the gaps created by data filtering. Finally, we calculate the work resumption index for 21 cities and 7 provinces in China (Figure 2) based on NTLs and UTI and verify the results with official statistics and facts.



Figure 2. Study area, including 21 cities and 7 provinces. 


\section{Materials and Methods}

2.1. Data

\subsubsection{Data I-NPP-VIIRS Night Time Lights}

In this study, the National Polar-orbiting Partnership Visible Infrared Imaging Radiometer Suite (NPP-VIIRS) Day /Night Band (DNB) daily night time lights data is used to calculate the work resumption index. Compared to the previous Defense Meteorological Satellite Program/Operational Linescan System (DMSP/OLS), VIIRS has higher radiometric accuracy and provides onboard calibration, which can guarantee the accuracy and stability of the data. In addition, its radiation measurements range from $3 \times 10^{-9} \mathrm{~W} \cdot \mathrm{cm}^{-2} \cdot \mathrm{sr}^{-1}$ to $0.02 \mathrm{~W} \cdot \mathrm{cm}^{-2} \cdot \mathrm{sr}^{-1}$, which ensures that the sensor can detect very low brightness without reaching saturation in high brightness regions. The daily NTLs data used in the study were NASA's daily Black Marble night time lights product suite (VNP46A1) [45] with $500 \mathrm{~m}$ spatial resolution and archived at NASA's Atmosphere Archive \& Distribution System (LAADS) Distributed Active Archive Center (DAAC) (https:/ /ladsweb.modaps.eosdis.nasa.gov/, accessed on 15 March 2020). Because of its high temporal resolution, the daily NTLs data is usually used for dynamic analysis of short-term events $[26,46]$. The NTLs data provided in this product is sensor radiation, so it is necessary to preprocess the original data to remove the influence of reflected moonlight, cloud and so on. Another product is monthly average radiance composite images using the daily image. Prior to averaging, the DNB data is filtered to exclude data impacted by stray light, lightning, lunar illumination and cloud-cover [47]. However, the lights from aurora, fires, boats and other temporal lights still exist in monthly composites. The temporal light of the city in the study will produce outliers, so the monthly images also need to be pre-processed.

\subsubsection{Data II-MODIS Land Surface Reflectance}

MODIS land surface reflectance product, MOD09A1 with $500 \mathrm{~m}$ spatial resolution was selected as the auxiliary data to preprocess the NTLs, which are available from NASA's LAADS DAAC data center (https: / / ladsweb.modaps.eosdis.nasa.gov / , accessed on 26 March 2020). MOD09A1 is an 8-day gridded level3 product in the Sinusoidal projection. Each MOD09A1 pixel contains the best possible L2G observation during 8 days as selected on the basis of high observation coverage, low view angle, the absence of clouds or cloud shadow and aerosol loading. Following the method proposed by Zhao et al. [26], the MODIS surface reflectance data was used to calculate moonlight radiation.

\subsubsection{Data III-Population Migration}

Baidu map big data of population migration (Baidu migration) conducts calculation and analysis using location-based service (LBS) big data, based on the Baidu cloud data analysis platform. It realizes the visualization of personal geographic space movement through mobile phone users' positioning information. The Baidu map migration data include the inter-city move-in and move-out size index and intra-city urban travel intensity. Here, we used the urban travel intensity (UTI) (http:/ / qianxi.baidu.com/, accessed on 17 March 2020), the indexation of ratio of the number of people traveling within the city to the number of people living in a city, to reflect the resumption of work.

\subsubsection{Data IV-Other}

Administrative boundary data were obtained from Big Earth Data Science Engineering Project (CASEarth) Data sharing service system [48]. In addition, land use data is essential urban land use categories in China mapping (EULUC) shared by Prof. Gong et al. [49]. The data divide urban land into five categories: residence, commercial, industrial, transportation and public management and service, which was used as the base map to eliminate the pixels of NTLs images that do not contribute to the calculation of work resumption index. 


\subsection{Method}

The process of calculating the work resumption index is shown as Figure 3:



Figure 3. The flowchart of calculating the work resumption index.

Preprocess with VIIRS-DNB daily night time lights. As mentioned above, the NPPVIIRS DNB daily data is probably affected by clouds, moonlight radiation (Figure 4) and other factors, so the original data need to be preprocessed. For moonlight radiation, Miller and Turner [50] proposed MT2009, a lunar spectral irradiation model of Top of Atmosphere (TOA), which is calculated with the distance between sun and moon, the distance between moon and earth, date and time. On this basis, Cao et al. [51] proposed the estimation model of DNB moonlight radiation:

$$
\mathrm{L}_{m}=\frac{E_{m}}{\pi} \rho \cos \left(\theta_{m}\right)
$$

where $E_{m}$ is the TOA lunar irradiance derived from the MT2009 model. $\theta_{m}$ is the lunar zenith angle. $\rho$ is land surface reflectance. Following the method proposed by Zhao et al. [26], the average of band 1, 2, 4 of the 8-day composite MODIS surface reflectance data was used instead of the TOA reflectance in the original method, which is affected by clouds. The lunar radiation $L_{m}$ is calculated for pixel in each night time light image according to Equation (1). Subtracting $L_{m}$ from the digital number (DN) of the original NTLs pixel (i.e., original NTLs radiation subtracts lunar radiation), the image illuminated by moonlight was eliminated and moonlight corrected images were obtained.

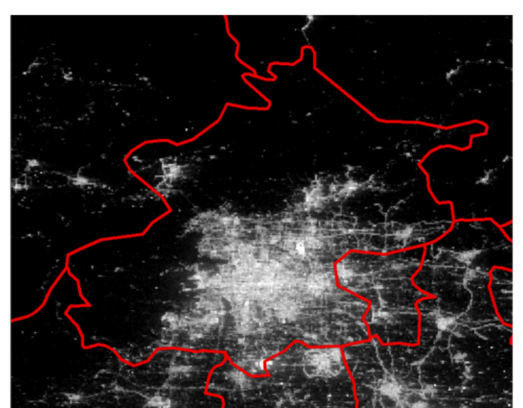

(a)

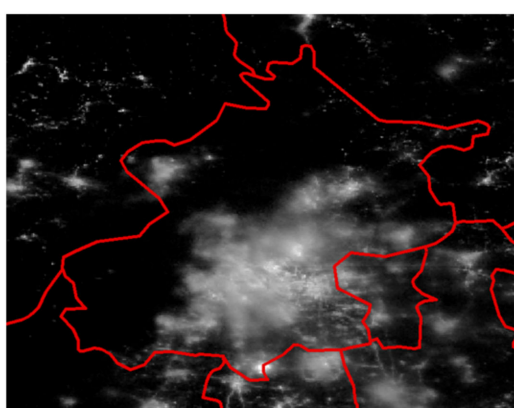

(b)

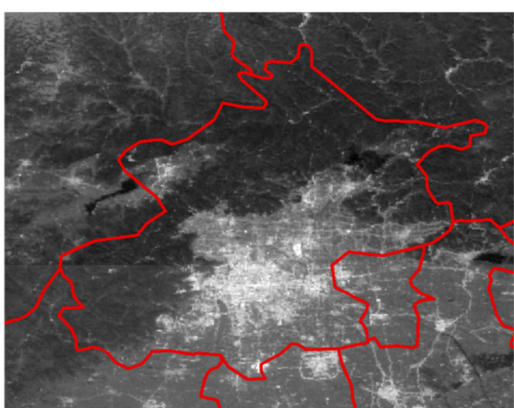

(c)

Figure 4. VIIRS DNB images under different conditions: (a) No cloud and moonlight pollution. (b) Images contaminated by clouds. (c) Images polluted by moonlight. 
Cloud reduces the night time light intensity and blurs light spatial detail features [52]. The cloud-mask flag in VNP46A1 was used to remove the "confidentially" cloudy pixels. Simultaneously, the snow/ice flag of the cloud mask data in VNPA1 was used to exclude areas covered by snow and ice. After the above processing, outliers might be still in the data. To reduce the influence of outliers, the noise of daily NTL data was removed using corresponding monthly composite images. Finally, we removed images still contaminated by clouds manually, due to errors in the cloud-mask flag. Specifically, each image for each city was checked manually. When the image is blurred as in Figure $4 \mathrm{~b}$, it indicates that the image is still covered by clouds and is deleted. The remaining images are all high-quality and cloud-free together without moonlight contamination.

The monthly composite images were compared with images of adjacent phases (for example, comparing images from February 2020 with images from January and March 2020) to eliminate the noise generated by transient light sources.

Remove residential pixels of night time lighting images. In the calculation of the work resumption index, the night time light changes in industrial areas, business areas, education areas and other areas, can directly reflect the degree of resumption of work, while the light change in residential areas cannot. Liu et al. [40] found that the lights in residential areas increased after the beginning of the lockdown. As the residential areas occupy a large area of city, it is necessary to eliminate the NTLs in the residential areas. EULUC data were used as the base map to extract the NTLs image pixels of the residential land-use category. When the area of residential land-use category in a pixel exceeds $50 \%$, the pixel was excluded to reduce the influence of night time lighting in a residential area as much as possible. The NTLs data of non-residential areas were obtained after removing.

Fill the gaps in night time lighting images. After preprocessing, a lot of gaps are left in the image that should be filled to calculate the work resumption index more accurately. The least-squares linear regression model for the per-pixel time series of the daily data was used to obtain the trend of NTLs data. Although scholars mostly chose the seasonal and trend decomposition using loess (STL) decomposition [29] method to obtain the NTLs trend, Eleanor C. Stokes et al. [53] found that the trend slope has a little difference using between the weighted least square linear regression methods and the STL decomposition approaches and the linear regression is much simpler. Next, the pixels' values of the gap were predicted and filled according to the trend of each pixel time series. Specifically, the daily brightness of lights (except for vacancies) for each pixel during the study period (from 10 February 2020 to 29 March 2020) was counted. A regression fit was made to every time-series data to obtain a linear equation. Then, the values at the vacancies were then estimated and filled. It is worth noting that the gap filling is not carried out when the image of a city has many gaps, which means that the area is seriously polluted by clouds in the period. In this study, the threshold was set to $20 \%$. No filling is done when the percentage of vacancies is higher than this number. Likewise, the work resumption index is also not calculated.

Calculate the work resumption index. Although many studies have been done on the resumption of work after public emergencies [7,9,43], the rate of work resumption after public emergencies has not been defined clearly [7]. Combined with existing research $[9,10,43,44]$, the resumption of work level can be reflected by the extent to which the brightness of NTLs (or urban travel intensity) from the Spring Festival holiday back to the normal working day. We proposed the work resumption index that approximates the degree of offline work resumption.

The calculation formula of the work resumption index WRI is shown as follows Equation (2):

$$
W R I_{N T L s}=\left(1-\frac{N T L_{\text {work }}-N T L_{t}}{N T L_{\text {work }}-N T L_{\text {holiday }}}\right) \times 100 \%
$$

where $N T L_{t}$ is the average DNB radiance of week $t$. The work resumption index was calculated each week starting from 10 February 2020 (The 17th day of the first lunar month) to 29 March 2020. NTL holiday is the average DNB radiance during the Spring Festival. 
As shown in Figure 5b, taking Beijing as an example, the urban travel intensity is low during the Spring Festival (from 25 January 2020 (the first day of the first lunar month) to 8 February 2020 (the 15th of the first lunar month, Lantern Festival)), whose level of work resumption generally assumes as zero. $N T L_{\text {work }}$ is the predicted NTLs radiation at the time of full resumption of work in 2020. Elvidge et al. [38] found that night time lights in China have been growing for several decades. We assume the same annual growth in night time lighting from 2018 to 2020. The increase from 2019 to 2020 was replaced with the increase from 2018 to 2019. China's Spring Festival holiday is usually in February. Generally, work resume completely in March, whether in factories, shopping malls, or schools. Therefore, based on the increase of NTLs from 2018 to 2019 increase $2018-2019^{2}$ and the NTLs radiation in March 2019 NTL $_{201903}$, the NTLs radiation without the impact of the epidemic in March $2020 N T L_{\text {work }}$ was predicted:

$$
N T L_{\text {work }}=N T L_{201903}+\text { increase }_{2018-2019}
$$

\begin{tabular}{ccccccccccccccc}
\hline \multirow{2}{*}{2019} & Jan & Jan & Jan & Jan & Jan & Feb & Feb & Feb & Feb & Feb & Feb & Feb & Feb & Mar \\
& 12 & 16 & 20 & 24 & 28 & 1 & 5 & 9 & 13 & 17 & 19 & 23 & 27 & 3 \\
\hline \multirow{2}{*}{2020} & Jan & Jan & Jan & Jan & Jan & Jan & Jan & Jan & Feb & Feb & Feb & Feb & Feb & Feb \\
& 1 & 5 & 9 & 13 & 17 & 21 & 25 & 29 & 2 & 6 & 8 & 12 & 16 & 20 \\
\hline \multicolumn{1}{c}{} & \multicolumn{1}{c}{ Chinese New Year } & \multicolumn{1}{c}{ Chinese Lantern Festival }
\end{tabular}

(a) 2019 and 2020 date comparison chart according to the Chinese lunar calendar.

Beijing urban travel intensity

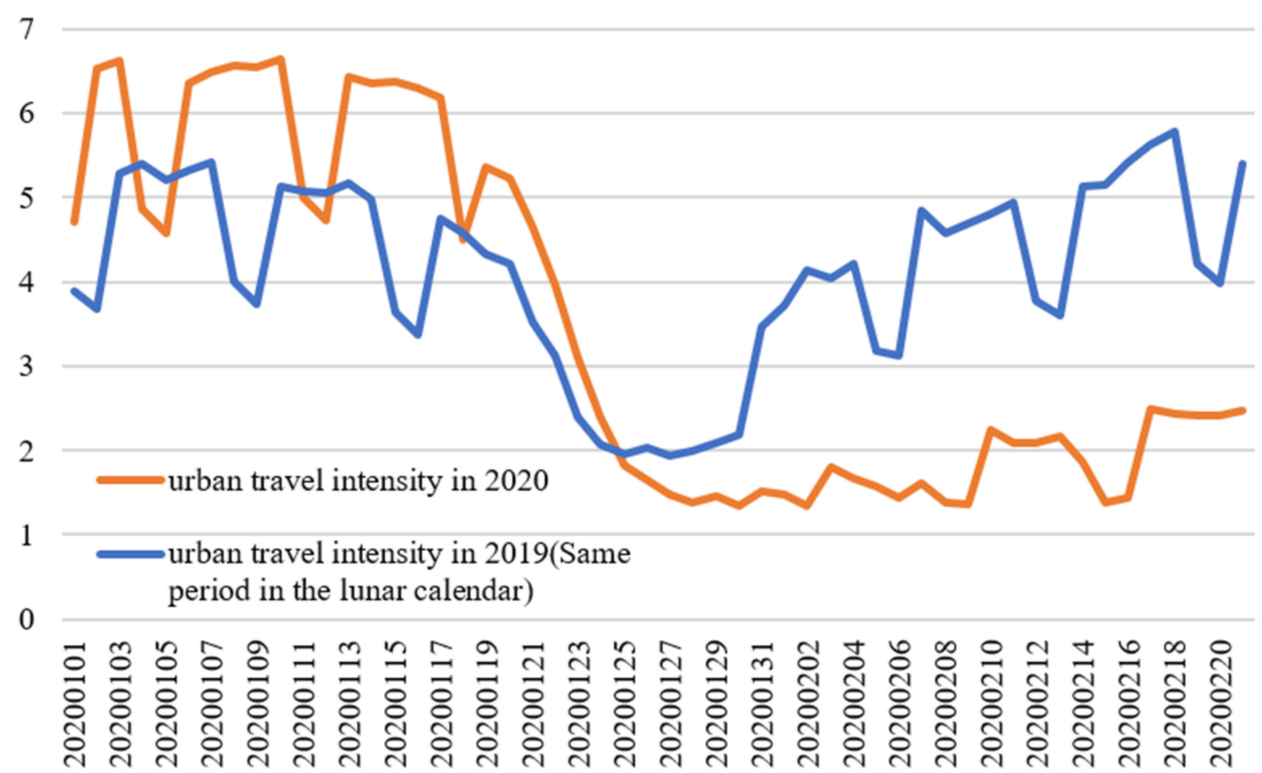

(b) Beijing urban travel intensity in 2020 and 2019.

Figure 5. (a) According to the Chinese lunar calendar, the dates of 2019 and 2020 correspond to each other. (b) Beijing urban travel intensity in 2020 and 2019. According to the Chinese lunar calendar, the dates of 2019 and 2020 correspond to each other. 2019 urban travel intensity is plotted against 2020 data for the same lunar date. The corresponding date of 2019 can be found in (a).

The calculation method of the work resumption index, based on urban travel intensity, is consistent with the NTLs method. It is shown as follows (4):

$$
W R I_{U T I}=\left(1-\frac{U T I_{\text {work }}-U T I_{t}}{U T I_{\text {work }}-U T I_{\text {holiday }}}\right) \times 100 \%
$$


where $U T I_{t}$ is the average urban travel intensity on weekdays of week $t$. As shown in Figure 5, urban travel intensity is significantly different on weekdays and weekends. For example, urban travel intensity is significantly lower on Saturday, 15 February and Sunday,16 February 2020, than on 10 to 14 February 2020 (weekdays). So, only the weekday data were selected. $U T I_{\text {holiday }}$ is the average urban travel intensity during the Spring Festival. UTI $I_{\text {work }}$ is the average urban travel intensity of normal working days before the Chinese New Year in 2020, because of the lack of data to predict the intensity of urban travel when work fully resumes in 2020.

VIIRS DNB data can reflect economic activities. Generally, the brighter the area is, the more economic activity there is [54]. Most of the travel of residents on working days is related to commuting. NTLs and urban travel intensity data reflect the work resumption level from different angles, so the average work resumption index obtained by NTLs and UTI is used to improve the accuracy. The final work resumption index is shown in Equation (5):

$$
W R I=\left(W R I_{N T L S}+W R I_{U T I}\right) / 2
$$

where $W R I_{N T L S}$ is work resumption index obtained by night time lights. $W R I_{U T I}$ is work resumption index obtained by urban travel intensity.

Verify the results. The studies of work resumption lack continuous and authoritative data during the epidemic. Therefore, how to evaluate the effectiveness of the measurement method becomes a major difficulty. Two methods were adopted to solve this problem:

(1) Compare with official statistics. The work resumption rate of the enterprises above designated size is the only official data of the resumption rate. The validity of the method can be demonstrated if the work resumption index has the same trend as the official data and is lower than the official data. This is because the rate of return to work is lower for small and medium-sized enterprises than for large firms [55].

(2) Give more information about whether it is consistent with the facts. During the resumption of work and production, the government issued a series of policy guidance and promotion. If our results are consistent with the time required by relevant policies, the accuracy of the method can also be verified.

\section{Results}

\subsection{Experimental Results}

First, the urban travel intensity around the Chinese New Year in 2020 and 2019 is shown in Figure 5b. In Beijing, the intensity of urban travel increased significantly on the seventh day of the Chinese New Year in 2019 (11 February 2019, corresponding to 31 January 2020 according to the lunar calendar), indicating that some people returned to work, while in 2020 it is not until the 17th day of the New Year (10 February 2020) that work begins to resume. The intensity of urban travel had resumed to the pre-Spring Festival in the fourth week of Chinese New Year 2019, while it remained low in 2020. So COVID-19 has seriously affected the resumption of work after the Spring Festival holiday. In addition, the intensity of urban travel is higher in 2020 than in 2019 before the Chinese New Year. Because China is constantly developing. Beijing as the capital is changing day by day, attracting a large number of workers every year. The activity of city residents is rising.

The top 21 cities were selected to calculate the work resumption index, according to the ranking of the emigration rate before the Spring Festival holiday. These cities have many large factories and these areas are economically developed, which means the demand for work resumption is more urgent. However, the epidemic situation makes it more difficult and thus, the estimation of the level of work resumption in these cities is more significant. In this study, the 21 cities were divided into three parts: provincial capital cities, Yangtze River Delta cities and Pearl River Delta cities.

Figure 6a-c shows the folding line chart of the weekly work resumption indexes for 21 cities based on NTLs. Since VIIRS DNB images have a lot of gaps after preprocessing, some cities have vacant values for a period. Overall, the level of work resumption is 
roughly increasing gradually. However, the growth in some cities is not quite smooth, but constantly fluctuating. The fluctuation amplitude of the provincial capital cities is smaller than that of the Yangtze River Delta cities. Due to the different angles of the NPPVIIRS satellites at different times, the DNB radiation has anisotropy [56]. The existence of oscillation is reasonable. However, there are some anomalies in Figure 6b. It is obvious that the work resumption index in the Yangtze River Delta cities suddenly increases in the second week. Because most of these cities are coastal cities with many ports. Large backlogs of orders make trade busy, which can lead to a sharp increase in NTLs luminous intensity.

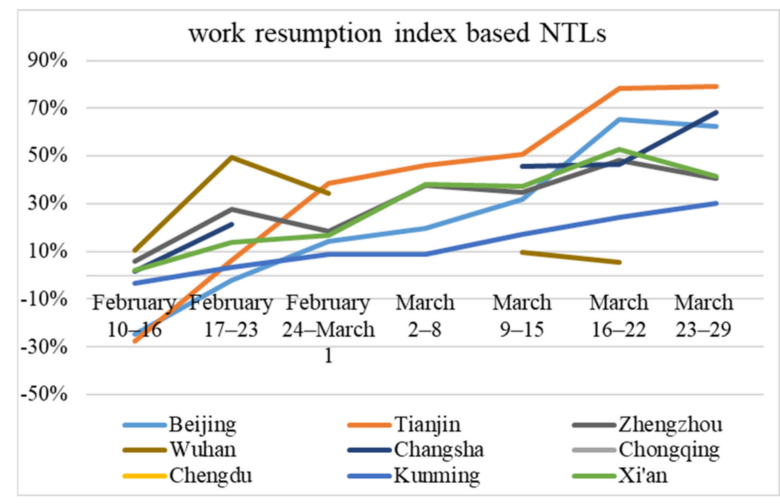

(a)

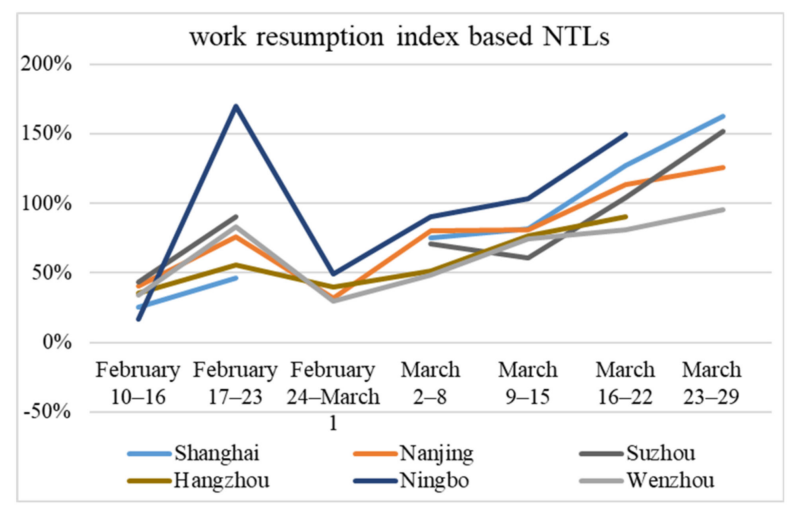

(b)

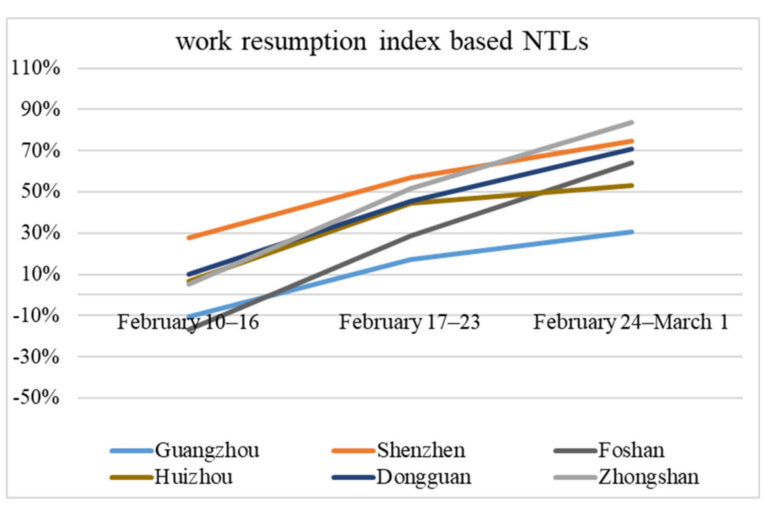

(c)

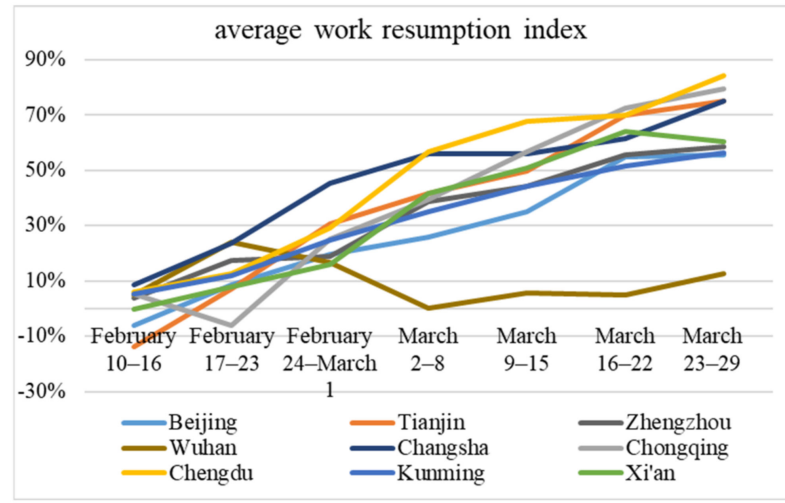

(d)

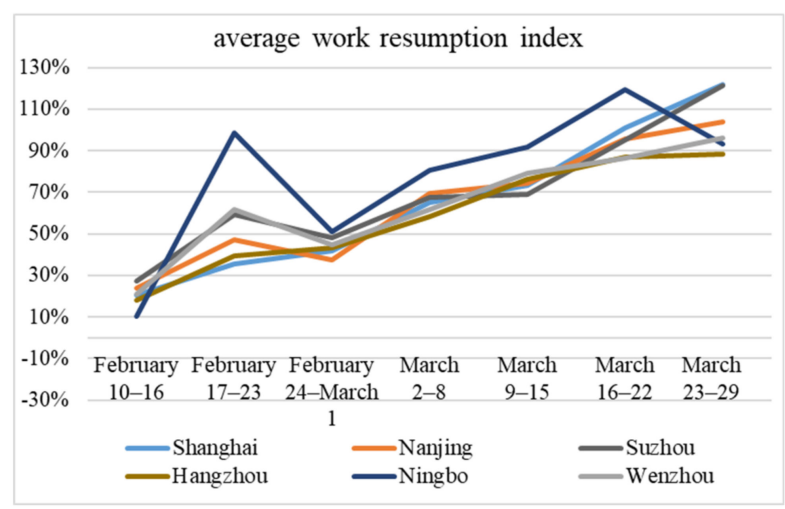

(e)

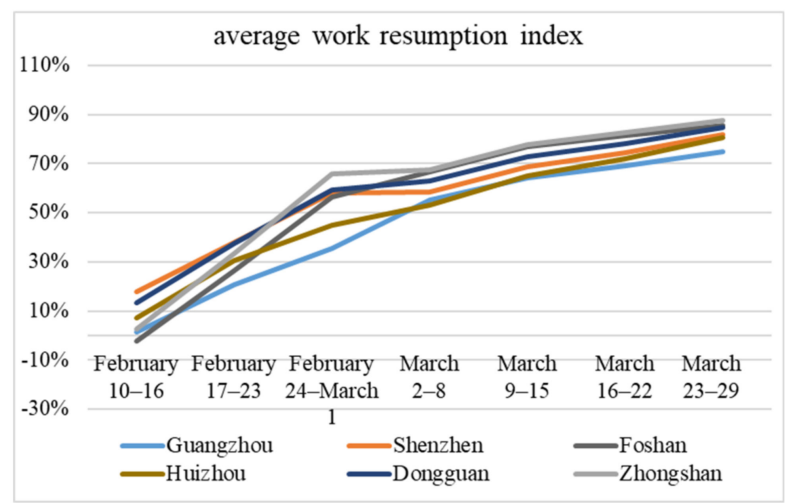

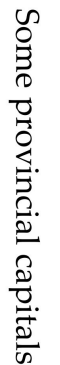

Figure 6. Work resumption indexes in 21 cities. The first lines $(\mathbf{a}, \mathbf{d})$ are the line chart of some provincial capitals, the second line $(\mathbf{b}, \mathbf{e})$ are Yangtze River Delta cities, the last line $(\mathbf{c}, \mathbf{f})$ are Pearl River Delta cities. The first column $(\mathbf{a}-\mathbf{c})$ are based on night-time light only, the second column $(\mathbf{d}-\mathbf{f})$ are averaging the work resumption rate based on NTLs and the urban travel intensity. 
The average work resumption index based on NTLs and the urban travel intensity is shown in Figure 6d-f. The vacant values in the results based on NTLs are directly replaced by the results based on urban travel intensity. Compared with the results obtained only by NTLs, the amplitude of the fluctuation has been significantly eased.

Next, the specific work resumption indexes of these 21 cities were analyzed. As shown in Table 1, from the first week after 9 February 2020, some cities began to resume work with different intensities, but the overall trend was low, even some of them were negative. Because the work resumption rate was assumed to be zero during the Chinese New Year, whereas night time lighting changes during holidays [29].

Table 1. Average work resumption indexes of 21 cities.

\begin{tabular}{|c|c|c|c|c|c|c|c|c|}
\hline & & $\begin{array}{c}\text { 10-16 } \\
\text { February }\end{array}$ & $\begin{array}{c}\text { 17-23 } \\
\text { February }\end{array}$ & $\begin{array}{c}24 \text { February- } \\
1 \text { March }\end{array}$ & $\begin{array}{c}2-8 \\
\text { March }\end{array}$ & $\begin{array}{c}\text { 9-15 } \\
\text { March }\end{array}$ & $\begin{array}{r}16-22 \\
\text { March }\end{array}$ & $\begin{array}{r}23-29 \\
\text { March }\end{array}$ \\
\hline \multirow{9}{*}{ Some provincial capitals } & Beijing & $-6.29 \%$ & $8.45 \%$ & $19.43 \%$ & $25.86 \%$ & $35.09 \%$ & $54.79 \%$ & $55.63 \%$ \\
\hline & Tianjin & $-14.00 \%$ & $7.26 \%$ & $30.45 \%$ & $41.63 \%$ & $49.69 \%$ & $70.01 \%$ & $74.94 \%$ \\
\hline & Zhengzhou & $3.86 \%$ & $17.51 \%$ & $19.01 \%$ & $38.77 \%$ & $44.29 \%$ & $55.64 \%$ & $58.64 \%$ \\
\hline & Wuhan & $4.92 \%$ & $23.99 \%$ & $16.80 \%$ & $0.18 \%$ & $5.53 \%$ & $4.83 \%$ & $12.72 \%$ \\
\hline & Changsha & $8.45 \%$ & $23.51 \%$ & $45.31 \%$ & $56.04 \%$ & $56.11 \%$ & $61.60 \%$ & $75.20 \%$ \\
\hline & Chongqing & $5.44 \%$ & $-6.12 \%$ & $25.23 \%$ & $39.53 \%$ & $56.81 \%$ & $72.49 \%$ & $79.36 \%$ \\
\hline & Chengdu & $5.89 \%$ & $12.52 \%$ & $29.00 \%$ & $56.56 \%$ & $67.75 \%$ & $69.73 \%$ & $84.13 \%$ \\
\hline & Kunming & $5.28 \%$ & $11.83 \%$ & $24.89 \%$ & $35.02 \%$ & $44.30 \%$ & $51.48 \%$ & $56.37 \%$ \\
\hline & $\mathrm{Xi}^{\prime}$ an & $-0.13 \%$ & $7.70 \%$ & $15.93 \%$ & $41.81 \%$ & $50.70 \%$ & $63.88 \%$ & $60.27 \%$ \\
\hline \multirow{6}{*}{ Yangtze River Delta cities } & Shanghai & $20.39 \%$ & $35.48 \%$ & $41.86 \%$ & $65.22 \%$ & $73.30 \%$ & $101.27 \%$ & $121.74 \%$ \\
\hline & Nanjing & $23.89 \%$ & $47.01 \%$ & $37.30 \%$ & $69.67 \%$ & $74.54 \%$ & $95.73 \%$ & $103.99 \%$ \\
\hline & Suzhou & $27.22 \%$ & $59.13 \%$ & $47.93 \%$ & $67.51 \%$ & $68.88 \%$ & $95.42 \%$ & $121.25 \%$ \\
\hline & Hangzhou & $18.20 \%$ & $39.48 \%$ & $43.45 \%$ & $58.54 \%$ & $76.22 \%$ & $87.01 \%$ & $88.37 \%$ \\
\hline & Ningbo & $10.58 \%$ & $98.64 \%$ & $51.18 \%$ & $80.53 \%$ & $91.87 \%$ & $119.24 \%$ & $93.31 \%$ \\
\hline & Wenzhou & $20.96 \%$ & $61.79 \%$ & $44.77 \%$ & $61.96 \%$ & $79.14 \%$ & $86.64 \%$ & $96.27 \%$ \\
\hline \multirow{6}{*}{ Pearl River Delta cities } & Guangzhou & $1.35 \%$ & $20.81 \%$ & $35.64 \%$ & $54.98 \%$ & $64.01 \%$ & $69.28 \%$ & $74.65 \%$ \\
\hline & Shenzhen & $17.65 \%$ & $38.13 \%$ & $58.14 \%$ & $58.45 \%$ & $68.75 \%$ & $74.60 \%$ & $81.66 \%$ \\
\hline & Foshan & $-2.30 \%$ & $26.60 \%$ & $56.32 \%$ & $66.64 \%$ & $76.96 \%$ & $81.30 \%$ & $85.42 \%$ \\
\hline & Huizhou & $6.99 \%$ & $30.71 \%$ & $44.79 \%$ & $53.12 \%$ & $65.18 \%$ & $71.89 \%$ & $80.70 \%$ \\
\hline & Dongguan & $13.40 \%$ & $37.54 \%$ & $59.28 \%$ & $63.15 \%$ & $72.78 \%$ & $78.19 \%$ & $84.77 \%$ \\
\hline & Zhongshan & $2.67 \%$ & $33.34 \%$ & $65.72 \%$ & $67.27 \%$ & $77.59 \%$ & $82.64 \%$ & $87.41 \%$ \\
\hline
\end{tabular}

By the end of February, the third week, resumption of work indexes in different cities had a wide range. Among the provincial capital cities except Wuhan, the work resumption index of Beijing, Zhengzhou and Xi' an were relatively low, only about $17 \%$, while Changsha reached $45.31 \%$. For the cities in the Yangtze River Delta, the work resumption indexes were higher than that of the capital cities ahead. The lowest was Nanjing, $37.30 \%$ and the highest was Ningbo of $51.18 \%$. In addition, the work resumption indexes in cities of the Pearl River Delta were slightly higher than that of the Yangtze River Delta. In Shenzhen, Foshan, Dongguan and Zhongshan, the work resumption indexes reached $55 \%$ or more. Among the 20 cities except for Wuhan, the highest work resumption index is Zhongshan $65.72 \%$ and the lowest is $\mathrm{Xi}^{\prime}$ an $15.93 \%$.

By the end of March, the work resumption indexes in most cities were over $70 \%$. The indexes in the Pearl River Delta cities were about $80 \%$, while the Yangtze River Delta cities have reached $90 \%$, or even fully resume work. However, the work resumption index in some provincial capitals is still relatively low. Beijing, Zhengzhou, Kunming and Xi'an only recovered to about $58 \%$.

Compared with the results of 21 cities, the speed of work resumption in economically developed coastal cities, such as the Pearl River Delta and the Yangtze River Delta, is faster than that of the mainland provincial capitals, especially at the end of February. Because the coastal cities have many large factories, enterprises, etc. and undertake a lot of import and export trades, they are more urgent to return to work. By the end of March, the gap 
between the inland city (such as Tianjin, Changsha, Chengdu, Chongqing, etc.) and the coastal city has been significantly reduced. However, the work resumption indexes were relatively low in Beijing and Zhengzhou, due to the severe epidemic situation and strict control policy. Beijing, as the political and cultural center of the country, took more cautious measures to resume work and production. The Beijing government required no more than $50 \%$ of employees of staff-intensive enterprises to be present on 24 February [57]. Henan Province is adjacent to Hubei Province and has a large population movement. As of 12 March 2020, Henan has the 3rd highest cumulative confirmed cases nationwide, after Hubei and Guangdong [58]. It had taken much more time until the full resumption of work.

As the city with the most serious epidemic situation in China, Wuhan is the last one fully recovered and the work resumption index has been basically zero due to the implementation of the lockdown policy. Until $11 \mathrm{March}$, the prevention and control headquarters of Hubei Province issued a notice to the society that enterprises should resume work and resume production no earlier than 24:00 on 20 March. Therefore, in the last week of March, Wuhan's work resumption index had increased to $12.72 \%$.

Since some areas of China, especially the southern and eastern coastal areas, are often covered by clouds, there are many gaping holes after preprocessing, which makes it impossible to calculate the work resumption index of the whole province precisely. Therefore, only seven provinces were selected for analysis (Table 2 and Figure 7).

Table 2. The work resumption index of 7 provinces.

\begin{tabular}{ccccc}
\hline & 10-16 February & Late February & Early March & Late March \\
\hline Hebei & $0.46 \%$ & $\mathbf{1 4 . 2 4} \%$ & $35.83 \%$ & $67.21 \%$ \\
Shanxi & $1.73 \%$ & $22.71 \%$ & $41.28 \%$ & $65.60 \%$ \\
Jiangsu & $12.22 \%$ & $51.94 \%$ & $61.79 \%$ & $89.74 \%$ \\
Shandong & $6.02 \%$ & $38.16 \%$ & $61.15 \%$ & $\mathbf{9 2 . 5 3} \%$ \\
Henan & $4.45 \%$ & $25.34 \%$ & $49.97 \%$ & $66.33 \%$ \\
Hunan & $9.15 \%$ & $28.83 \%$ & $47.38 \%$ & $\mathbf{5 7 . 0 7 \%}$ \\
Shaanxi & $1.22 \%$ & $22.42 \%$ & $52.78 \%$ & $64.19 \%$ \\
\hline
\end{tabular}

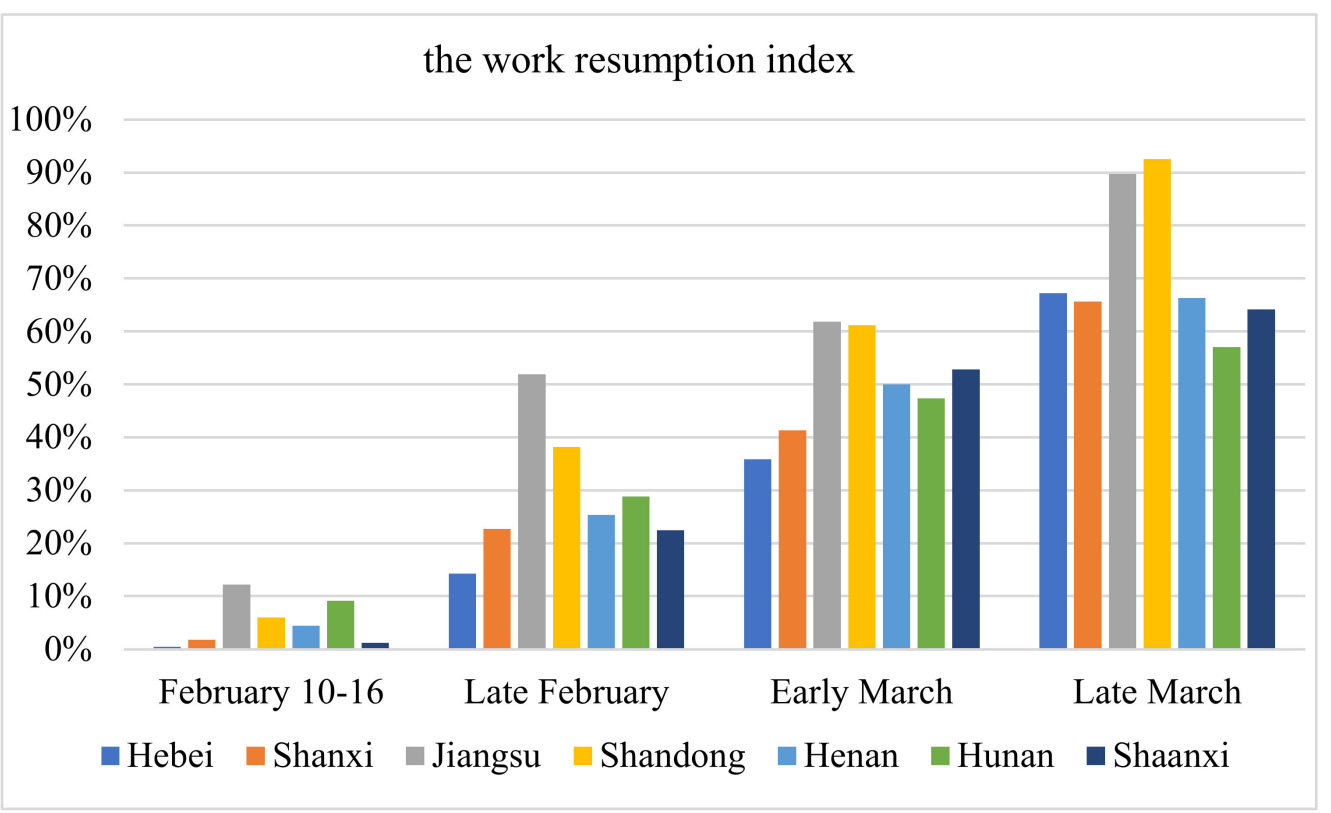

Figure 7. The histogram of the work resumption index of 7 provinces.

From Figure 7, it can be also observed that the level of work resumption has been steadily improved. In the week after 9 February, most areas have begun to return to work. 
In late February, the degree of resumption of work varies between different provinces. Jiangsu and Shandong had a higher work resumption index, while the index of Hebei was the lowest, i.e., $14.24 \%$ and other provinces were about $25 \%$. In Early March, the gap of work resumption in each province had decreased. The highest work resumption index was Jiangsu, $61.79 \%$, while the lowest still was Hebei, $35.83 \%$. By the end of March, the work resumption in Jiangsu and Shandong has recovered to about $90 \%$, while other provinces only were about $60 \%$, such as Hunan, the lowest rate of $57.07 \%$.

At the provincial level, we still get the same conclusion as before: the rate of returning to work in coastal such as Jiangsu and Shandong are higher than that in inland areas.

\subsection{Verifing Results}

Compare with official statistics. Compared the resumption of work index in 8 provinces and municipalities with the level of enterprises above designated size resumption issued by the national development and Reform Commission, it can be seen the trend of work resumption in all regions is the same as that in the official statistics, shown as Figure 8. Small and medium-sized enterprises are struggling to survive [59] and they are recovering more slowly than larger firms. The work resumption index obtained by our method estimates the overall level of resumption of work. It can be seen in Figure 8 that the index is also lower than the official data, which proves the validity of the proposed method. Furthermore, the gap between the large and medium-sized enterprises is constantly narrowing. This indicates that small and medium-sized enterprises may have returned to work and production and the economy is recovering step by step during this period.

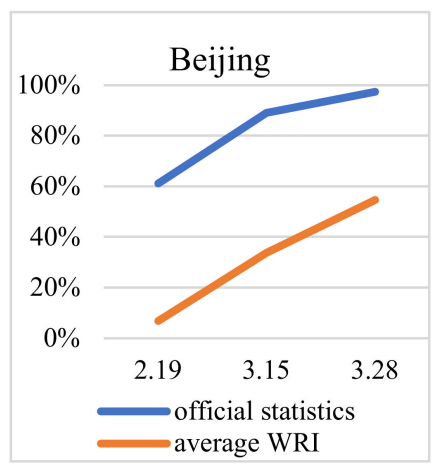

(a)



(e)

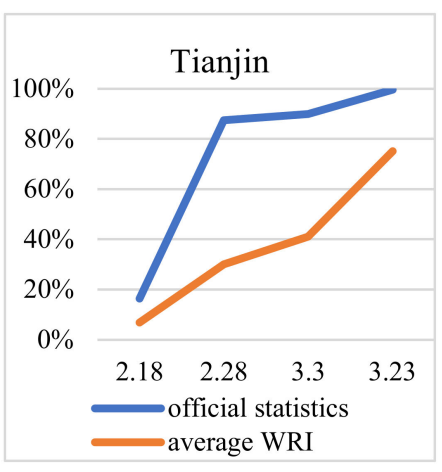

(b)

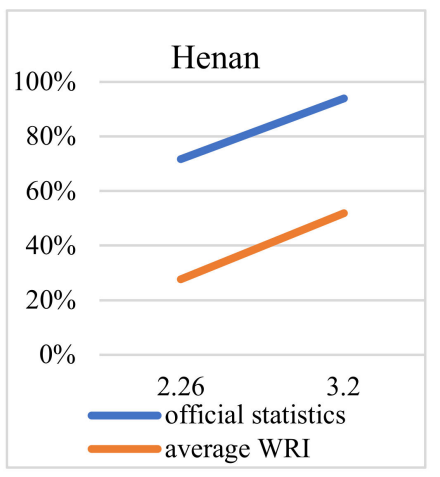

(f)

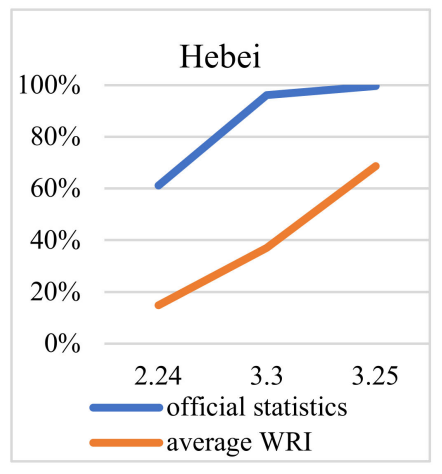

(c)

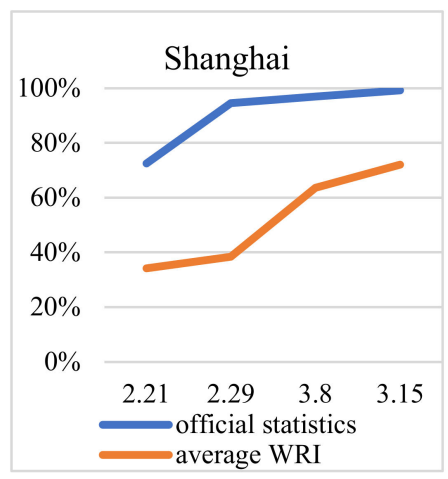

(g)



(d)



(h)

Figure 8. Comparison of work resumption indexes based official statistics and our method in (a) Beijing, (b) Tianjin, (c) Hebei, (d) Shandong, (e) Henan, (f) Jiangsu, (g) Shanghai, (h) Hunan.

Verify with facts. In addition to Hubei Province, other regions also have successively issued notices that all kinds of enterprises to resume work no earlier than 24:00 on 
9 February, except for essential enterprises [60]. Therefore, the work resumption indexes from 10 to 16 February should be the minimum. The analysis results agree with the real situation. In Hubei, the epidemic situation had been effectively controlled in February after unremitting efforts. The number of newly diagnosed cases in Wuhan by March had also been greatly reduced and people's lives were gradually restored. As previously mentioned, the government required Hubei to resume work no earlier than 20 March. In the results, the work resumption index in Wuhan had been at a low level and increased significantly in the last week of March, which is also in line with the actual situation.

\section{Discussion}

We calculated the work resumption index based on night time lights and urban travel intensity. The 21cities and seven provinces were selected as examples for discussion, as the southern areas and eastern coastal areas are mostly covered by clouds and the northeast area is covered by ice and snow in February and March. These regions have many abnormal pixels, which cannot reflect the NTLs changes in the whole region. The method we propose may not be suitable for areas covered by clouds or snow for long periods. In addition, it can be seen an anomaly in the week 2 work resumption index based on luminosity in Yangtze River Delta cities and Wuhan. Developed light industry and foreign trade in the Yangtze River Delta cities may cause a sharp increase in the luminosity of NTLs. The epidemic in Wuhan is most severe in February. The control of the epidemic and the delivery of medical supplies and living materials make the night time lights change.

The NPP-VIIRS passes by at around 1:30 a.m. local time. The VIIRS data may do not fully present the activity after working hours as the entertainment venue is still closed. However, the night time lighting in the commercial area can reflect the degree of resumption of work in the commercial area. As long as the lighting changes are related to the work resumption, whether, in commercial or industrial areas, or other areas, we think it is helpful. In the study, only the night time light images of non-residential areas were extracted to improve the estimation accuracy. However, the spatial resolution of VIIRS DNB data is $500 \mathrm{~m}$, which is relatively high. There may be mixed (i.e., residential and non-residential) areas in a pixel. Although it is impossible to avoid this situation, our method may be more effective than directly using the night time lighting data of the whole city to estimate the reworking level [43]. In the future, we expect to use higher resolution night time lighting data to delineate a more accurate NTLs image in non-residential areas.

Due to technical limitations, the VIIRS DNB data lack sensitivity to the blue light spectrum [61]. The VIIRS DNB radiation sensitivity is insufficient for the identification of all outdoor light sources, as the spectrum below $500 \mathrm{~nm}$ is emitted with high ratios from modern, efficient lighting such as LED-road lighting or Xenon vehicle lighting. However, during the resumption of work, apparent changes in night time lighting were observed. The VIIRS DNB data are still feasible as a proxy to monitor the resumption of economic activity levels [41]. In addition, the VIIRS DNB data can be obtained free of charge for daily worldwide night time light images, which are widely used in night time light research [61]. We also expect to use multispectral sensors covering the blue to the NIR range to study urban lighting more effectively in the future. Artificial night time skyglow as a supplement to night time light remote sensing data is affected by air quality [62,63]. Air pollution decreases due to COVID-19 city lockdown [64,65]. However, to our knowledge, the effect of air quality on artificial skyglow has not been quantified. Similarly, no studies have determined the specific contribution of artificial skyglow to night time light remote sensing data. Only studies suggest that the diffuse light observed around cities is a direct observation of the composition of urban skyglow that scatters upward [66].

Baidu Maps has only released urban travel intensity data for China from January to May 2020 and during the National Day holiday. So, our method can only get the resumption index for each city in China during that period. When extending to other countries and regions, night time light data can be considered combined with local population travel data. 
The results were compared with the relevant data to verify the effectiveness of the calculation of the work resumption index. However, the methods only verify the effectiveness of the changing pattern. The effectiveness of a single independent value is not verified; for example, it is impossible to judge whether the work resumption index $55.63 \%$ of Beijing is accurate.

Unfortunately, the work resumption index only represents the level of offline work resumption. Some companies worked from home and the actual level of return to work may be higher than our results. In the future, more datasets will be used to estimate the trend by quantitative analysis. Furthermore, the relationship between the work resumption index and other data such as the regional economy, the number of migrant workers and the severity of the epidemic situation will be considered in the future to analyze the influencing factors of the resumption of work. NTLs has been demonstrated to have a close relationship with the economy $[54,67]$. It can be applied to the investigation of socioeconomic conditions after a pandemic.

\section{Conclusions}

To address the lack of continuous resumption rate data under the epidemic, we proposed to analyze the work resumption level by combining night time lights data and urban travel intensity data. Considering the gap between the recovery of night time light intensity and the resumption rate, the images of residential areas were excluded. Meanwhile, NTLs data were pre-processed, such as lunar radiation correction, to obtain as much valid data as possible. To improve the estimation accuracy, only weekday urban travel intensity data were used for the study. We found that the COVID-19 epidemic severely impacted the resumption of work in China after the Spring Festival. Work started to resume everywhere from 10 February and the index of resumption gradually increased. By the end of March, the index of resumption of work in most areas exceeded $70 \%$ and some cities have achieved complete resumption of work.

In addition, the work resumption index varies greatly from region to region. Generally, the process of work resumption in coastal areas is faster, such as cities in the Yangtze River Delta and the Pearl River Delta, while the process is relatively slow in inland cities such as Beijing and Zhengzhou. Wuhan began to resume work until the last week of March. Local governments should formulate different policies according to the actual situation. Each company must go through prevention of epidemics before resuming work to avoid the gathering of infections among employees.

The results were verified by official statistics and facts, which demonstrate that remote sensing images of night time lights and urban travel intensity data can be effectively used for resumption studies under the impact of the epidemic. This not only enriches the applied research of night time lighting data but also provides new perspectives on the socio-economic impact of the epidemic. The process of recovering social production and life can provide a reference for the local government to evaluate the implementation effect of the policy and the extent of the loss of the national economy during the epidemic. Government statistics have a lag. Some media reports lack credibility. Our results can provide a reference for the government to make timely changes to the resumption of work and prevention policies. In addition, the combination of remote sensing data (night time lights) and ground-based statistics (urban travel intensity) greatly improves the accuracy of the results.

Since the night light data can be affected by other factors easily, such as cloud and moonlight and snow, a preprocessing step should be done for the daily NTLs image VNP46A1. The lack of data due to the cloud also limits the application of daily night time light data. In the future, we look forward to using the new product VNP46A2 [45], which provides BRDF-Corrected NTLs, to do research. In addition, we will compare with the resumption level of China in 2021.

In conclusion, this study has important implications for the estimation of the work resumption rate, which provided a new method to dynamically estimate the level of work 
resumption using night time lighting data and urban travel intensity. In addition, this study may be extended to other countries and regions to estimate the economic impact of the epidemic.

Author Contributions: Conceptualization, Suzheng Tian, Lizhe Wang and Ruyi Feng; methodology, Suzheng Tian, Ruyi Feng, Ji Zhao and Lizhe Wang; validation, Suzheng Tian; formal analysis, Suzheng Tian; data curation, Suzheng Tian; writing—original draft, Suzheng Tian; writing—review and editing, Ruyi Feng and Lizhe Wang. All authors reviewed the manuscript. All authors have read and agreed to the published version of the manuscript.

Funding: This work was supported in part by the National Natural Science Foundation of China (No. 41925007) and the National Natural Science Foundation of China (No. U1711266) and the Hubei Key Laboratory of Regional Development and Environmental Response (Hubei University) (No. 2020(B)003) and the Hong Kong Scholars Program (No. XJ2020025).

Institutional Review Board Statement: Not applicable.

Informed Consent Statement: Not applicable.

Data Availability Statement: Pre-processed weekly composite night time lights images and the work resumption index data calculated based on night time lights data and urban travel intensity data are available from https:/ / doi.org/10.6084/m9.figshare.14316638.v2 (accessed on 1 April 2021).

Acknowledgments: We thank the editors and the reviewers for their valuable comments and suggestions.

Conflicts of Interest: The authors declare no conflict of interest.

\section{References}

1. World Health Organization (WHO). Coronavirus. Available online: https://www.who.int/health-topics/coronavirus (accessed on 15 April 2020).

2. World Health Organization (WHO). Novel Coronavirus (2019-nCoV), Situation Report-3. Available online: https://www.who. int/docs / default-source/coronaviruse/situation-reports/20200123-sitrep-3-2019-ncov.pdf (accessed on 15 April 2020).

3. Kupferschmidt, K.; Cohen, J. Can China's COVID-19 strategy work elsewhere? Science 2020, 367, 1061-1062. [CrossRef] [PubMed]

4. McKinsey \& Company. COVID-19: Implications for Business. Available online: https://www.mckinsey.com/business-functions / risk/our-insights/covid-19-implications-for-business\# (accessed on 15 April 2020).

5. Scafa, F.; Calsamiglia, G.; Tonini, S.; Lumelli, D.; Lanfranco, A.; Gentile, E.; Berzolari, F.G.; Candura, S.M. Return to Work after Coronary Angioplasty or Heart Surgery A 5-Year Experience with the “CardioWork" Protocol. J. Occup. Environ. Med. 2012, 54, 1545-1549. [CrossRef] [PubMed]

6. Nishino, A.; Sakurai, Y.; Tsuji, I.; Arai, H.; Uenohara, H.; Suzuki, S.; Li, J.H. Resumption of work after aneurysmal subarachnoid hemorrhage in middle-aged Japanese patients. J. Neurosurg. 1999, 90, 59-64. [CrossRef]

7. Nie, L.; Fu, J.; Yi, C.; Yang, D. Measuring Enterprise's Offline Resumption with Mobile Device Positioning Data. Data Anal. Knowl. Discov. 2020, 4, 38-49.

8. Gan, M.; Tian, Y.; Zhang, W.; Zhao, X. Modeling and Relevance Analysis of Urban Epidemic Transmission and Work Resumption Intensity. J. Syst. Simul. 2020, 32, 2258.

9. Xu, X.L.; Wang, S.H.; Dong, J.H.; Shen, Z.C.; Xu, S.W. An analysis of the domestic resumption of social production and life under the COVID-19 epidemic. PLoS ONE 2020, 15, e0236387. [CrossRef]

10. Li, J.; Chu, B.; Chai, N.; Wu, B.; Shi, B.; Ou, F. Work resumption rate and migrant workers' income during the COVID-19 Pandemic. Front. Public Health 2021, 9, 464.

11. Cao, C.; Chang, C.; Xu, M.; Zhao, J.; Gao, M.; Zhang, H.; Guo, J.; Guo, J.; Dong, L.; He, Q. Epidemic risk analysis after the Wenchuan Earthquake using remote sensing. Int. J. Remote Sens. 2010, 31, 3631-3642. [CrossRef]

12. Yang, C.; Yu, M.; Li, Y.; Hu, F.; Jiang, Y.; Liu, Q.; Sha, D.; Xu, M.; Gu, J. Big Earth data analytics: A survey. Big Earth Data 2019, 3, 83-107. [CrossRef]

13. Elvidge, C.D.; Baugh, K.E.; Kihn, E.A.; Kroehl, H.W.; Davis, E.R. Mapping city lights with nighttime data from the DMSP operational linescan system. Photogramm. Eng. Remote Sens. 1997, 63, 727-734.

14. Elvidge, C.D.; Cinzano, P.; Pettit, D.R.; Arvesen, J.; Sutton, P.; Small, C.; Nemani, R.; Longcore, T.; Rich, C.; Safran, J.; et al. The Nightsat mission concept. Int. J. Remote Sens. 2007, 28, 2645-2670. [CrossRef]

15. Imhoff, M.L.; Lawrence, W.T.; Stutzer, D.C.; Elvidge, C.D. A technique for using composite DMSP/OLS “city lights" satellite data to map urban area. Remote Sens. Environ. 1997, 61, 361-370. [CrossRef]

16. Zhang, Q.L.; Seto, K.C. Mapping urbanization dynamics at regional and global scales using multi-temporal DMSP/OLS nighttime light data. Remote Sens. Environ. 2011, 115, 2320-2329. [CrossRef]

17. Liu, Z.F.; He, C.Y.; Zhang, Q.F.; Huang, Q.X.; Yang, Y. Extracting the dynamics of urban expansion in China using DMSP-OLS nighttime light data from 1992 to 2008. Landsc. Urban Plan. 2012, 106, 62-72. [CrossRef] 
18. Lan, T.; Shao, G.F.; Xu, Z.B.; Tang, L.N.; Sun, L. Measuring urban compactness based on functional characterization and human activity intensity by integrating multiple geospatial data sources. Ecol. Indic. 2021, 121, 107177. [CrossRef]

19. Li, F.G.; Li, E.Z.; Zhang, C.; Samat, A.; Liu, W.; Li, C.M.; Atkinson, P.M. Estimating Artificial Impervious Surface Percentage in Asia by Fusing Multi-Temporal MODIS and VIIRS Nighttime Light Data. Remote Sens. 2021, 13, 212. [CrossRef]

20. Xia, N.; Li, M.; Cheng, L. Mapping Impacts of Human Activities from Nighttime Light on Vegetation Cover Changes in Southeast Asia. Land 2021, 10, 185. [CrossRef]

21. Shi, K.F.; Yu, B.L.; Huang, Y.X.; Hu, Y.J.; Yin, B.; Chen, Z.Q.; Chen, L.J.; Wu, J.P. Evaluating the Ability of NPP-VIIRS Nighttime Light Data to Estimate the Gross Domestic Product and the Electric Power Consumption of China at Multiple Scales: A Comparison with DMSP-OLS Data. Remote Sens. 2014, 6, 1705-1724. [CrossRef]

22. Sutton, P.; Roberts, C.; Elvidge, C.; Meij, H. A comparison of nighttime satellite imagery and population density for the continental united states. Photogramm. Eng. Remote Sens. 1997, 63, 1303-1313.

23. Lo, C.P. Modeling the population of China using DMSP operational linescan system nighttime data. Photogramm. Eng. Remote Sens. 2001, 67, 1037-1047.

24. Guo, B.; Bian, Y.; Zhang, D.M.; Su, Y.; Wang, X.X.; Zhang, B.; Wang, Y.; Chen, Q.J.; Wu, Y.R.; Luo, P.P. Estimating Socio-Economic Parameters via Machine Learning Methods Using Luojia1-01 Nighttime Light Remotely Sensed Images at Multiple Scales of China in 2018. IEEE Access 2021, 9, 34352-34365. [CrossRef]

25. Li, X.; Chen, F.R.; Chen, X.L. Satellite-Observed Nighttime Light Variation as Evidence for Global Armed Conflicts. IEEE J. Sel. Top. Appl. Earth Obs. Remote Sens. 2013, 6, 2302-2315. [CrossRef]

26. Zhao, X.Z.; Yu, B.L.; Liu, Y.; Yao, S.J.; Lian, T.; Chen, L.J.; Yang, C.S.; Chen, Z.Q.; Wu, J.P. NPP-VIIRS DNB Daily Data in Natural Disaster Assessment: Evidence from Selected Case Studies. Remote Sens. 2018, 10, 1526. [CrossRef]

27. Elvidge, C.D.; Ghosh, T.; Baugh, K.; Zhizhin, M.; Hsu, F.C.; Katada, N.S.; Penalosa, W.; Hung, B.Q. Rating the Effectiveness of Fishery Closures With Visible Infrared Imaging Radiometer Suite Boat Detection Data. Front. Mar. Sci. 2018, 5, 132. [CrossRef]

28. Sarangi, R.K.; Jaiganesh, S.N.N. VIIRS boat detection (VBD) product-based night time fishing vessels observation in the Arabian Sea and Bay of Bengal Sub-regions. Geocarto Int. 2021. [CrossRef]

29. Roman, M.O.; Stokes, E.C. Holidays in lights: Tracking cultural patterns in demand for energy services. Earths Future 2015, 3 , 182-205. [CrossRef]

30. Chen, J.D.; Gao, M.; Cheng, S.L.; Liu, X.; Hou, W.X.; Song, M.L.; Li, D.; Fan, W. China's city-level carbon emissions during 1992-2017 based on the inter-calibration of nighttime light data. Sci. Rep. 2021, 11, 1-13.

31. Lu, X.M.; Zhang, X.Y.; Li, F.J.; Cochrane, M.A.; Ciren, P. Detection of Fire Smoke Plumes Based on Aerosol Scattering Using VIIRS Data over Global Fire-Prone Regions. Remote Sens. 2021, 13, 196. [CrossRef]

32. Liu, H.; Ma, L.; Xu, L. Estimating spatiotemporal dynamics of county-level fossil fuel consumption based on integrated nighttime light data. J. Clean. Prod. 2021, 278, 123427. [CrossRef]

33. Elvidge, C.D.; Zhizhin, M.; Baugh, K.; Hsu, F.-C.; Ghosh, T. Methods for global survey of natural gas flaring from visible infrared imaging radiometer suite data. Energies 2016, 9, 14. [CrossRef]

34. Hudecheck, M.; Sirén, C.; Grichnik, D.; Wincent, J. Monitoring the COVID-19 crisis from space. MIT Sloan Manag. Rev. 2020, 1-11. Available online: https://sloanreview.mit.edu/article/monitoring-the-COVID-19-crisis-from-space/ (accessed on 16 August 2020).

35. Beyer, R.C.; Franco-Bedoya, S.; Galdo, V. Examining the economic impact of COVID-19 in India through daily electricity consumption and nighttime light intensity. World Dev. 2021, 140, 105287. [CrossRef] [PubMed]

36. Miller, S.D.; Straka, W.C.; Yue, J.; Seaman, C.J.; Xu, S.; Elvidge, C.D.; Hoffmann, L.; Azeem, I. The Dark Side of Hurricane Matthew Unique Perspectives from the VIIRS Day/Night Band. Bull. Am. Meteorol. Soc. 2018, 99, 2561-2574. [CrossRef]

37. Li, X.; Li, D.R.; Xu, H.M.; Wu, C.Q. Intercalibration between DMSP/OLS and VIIRS night-time light images to evaluate city light dynamics of Syria's major human settlement during Syrian Civil War. Int. J. Remote Sens. 2017, 38, 5934-5951. [CrossRef]

38. Straka, W.; Kondragunta, S.; Wei, Z.; Zhang, H.; Miller, S.D.; Watts, A. Examining the Economic and Environmental Impacts of COVID-19 Using Earth Observation Data. Remote Sens. 2020, 13, 5. [CrossRef]

39. Anand, A.; Kim, D.-H. Pandemic Induced Changes in Economic Activity around African Protected Areas Captured through Night-Time Light Data. Remote Sens. 2021, 13, 314. [CrossRef]

40. Liu, Q.; Sha, D.X.; Liu, W.; Houser, P.; Zhang, L.Y.; Hou, R.Z.; Lan, H.; Flynn, C.; Lu, M.Y.; Hu, T.; et al. Spatiotemporal Patterns of COVID-19 Impact on Human Activities and Environment in Mainland China Using Nighttime Light and Air Quality Data. Remote Sens. 2020, 12, 1576. [CrossRef]

41. Elvidge, C.D.; Ghosh, T.; Hsu, F.-C.; Zhizhin, M.; Bazilian, M. The Dimming of Lights in China during the COVID-19 Pandemic. Remote Sens. 2020, 12, 2851. [CrossRef]

42. Elvidge, C.D.; Hsu, F.-C.; Baugh, K.E.; Ghosh, T. National trends in satellite-observed lighting 1992-2012. In Global Urban Monitoring and Assessment through Earth Observation; Weng, Q., Ed.; Taylor \& Francis Group: Boca Raton, FL, USA; London, UK; New York, NY, USA, 2014; Volume 23, pp. 97-118.

43. Lan, T.; Shao, G.; Tang, L.; Xu, Z.; Zhu, W.; Liu, L. Quantifying spatiotemporal changes in human activities induced by COVID-19 pandemic using daily nighttime light data. IEEE J. Sel. Top. Appl. Earth Obs. Remote Sens. 2021, 14, 2740-2753. [CrossRef]

44. Yin, R.; He, G.; Jiang, W.; Peng, Y.; Zhang, Z.; Li, M.; Gong, C. Night-Time Light Imagery Reveals China's City Activity During the COVID-19 Pandemic Period in Early 2020. IEEE J. Sel. Top. Appl. Earth Obs. Remote Sens. 2021, 14, 5111-5122. [CrossRef] 
45. Roman, M.O.; Wang, Z.S.; Sun, Q.S.; Kalb, V.; Miller, S.D.; Molthan, A.; Schultz, L.; Bell, J.; Stokes, E.C.; Pandey, B.; et al. NASA's Black Marble nighttime lights product suite. Remote Sens. Environ. 2018, 210, 113-143. [CrossRef]

46. Zheng, Y.M.; Shao, G.F.; Tang, L.N.; He, Y.R.; Wang, X.R.; Wang, Y.N.; Wang, H.W. Rapid Assessment of a Typhoon Disaster Based on NPP-VIIRS DNB Daily Data: The Case of an Urban Agglomeration along Western Taiwan Straits, China. Remote Sens. 2019, 11, 1709. [CrossRef]

47. Elvidge, C.D.; Baugh, K.; Zhizhin, M.; Hsu, F.C.; Ghosh, T. VIIRS night-time lights. Int. J. Remote Sens. 2017, 38, 5860-5879. [CrossRef]

48. National Basic Geographic Information Center. 2013 China Administrative Region Regionalization Data Set; National Basic Geographic Information Center: Beijing, China, 2017. [CrossRef]

49. Gong, P.; Chen, B.; Li, X.C.; Liu, H.; Wang, J.; Bai, Y.Q.; Chen, J.M.; Chen, X.; Fang, L.; Feng, S.L.; et al. Mapping essential urban land use categories in China (EULUC-China): Preliminary results for 2018. Sci. Bull. 2020, 65, 182-187. [CrossRef]

50. Miller, S.D.; Turner, R.E. A Dynamic Lunar Spectral Irradiance Data Set for NPOESS/VIIRS Day/Night Band Nighttime Environmental Applications. IEEE Trans. Geosci. Remote Sens. 2009, 47, 2316-2329. [CrossRef]

51. Cao, C.Y.; Shao, X.; Uprety, S. Detecting Light Outages After Severe Storms Using the S-NPP/VIIRS Day/Night Band Radiances. IEEE Trans. Geosci. Remote Sens. 2013, 10, 1582-1586. [CrossRef]

52. Baugh, K.; Hsu, F.-C.; Elvidge, C.D.; Zhizhin, M. Nighttime lights compositing using the VIIRS day-night band: Preliminary results. Proc. Asia-Pac. Adv. Netw. 2013, 35, 70-86. [CrossRef]

53. Stokes, E.C.; Seto, K.C. Characterizing urban infrastructural transitions for the Sustainable Development Goals using multitemporal land, population, and nighttime light data. Remote Sens. Environ. 2019, 234, 111430. [CrossRef]

54. Li, X.; Xu, H.M.; Chen, X.L.; Li, C. Potential of NPP-VIIRS Nighttime Light Imagery for Modeling the Regional Economy of China. Remote Sens. 2013, 5, 3057-3081. [CrossRef]

55. Dai, R.; Feng, H.; Hu, J.; Jin, Q.; Li, H.; Wang, R.; Wang, R.; Xu, L.; Zhang, X. The impact of COVID-19 on small and medium-sized enterprises (SMEs): Evidence from two-wave phone surveys in China. China Econ. Rev. 2021, 67, 101607. [CrossRef]

56. Li, X.; Ma, R.Q.; Zhang, Q.L.; Li, D.R.; Liu, S.S.; He, T.; Zhao, L.X. Anisotropic characteristic of artificial light at night-Systematic investigation with VIIRS DNB multi-temporal observations. Remote Sens. Environ. 2019, 233, 111357. [CrossRef]

57. The People's Government of Beijing Municipality. Beijing Municipal Bureau of Urban Management and Comprehensive Administrative Law Enforcement, Beijing Municipal Housing and Urban-Rural Development Commission, Beijing Municipal Emergency Management Bureau, Beijing Municipal Health and Wellness Commission, and Beijing Municipal Market Supervision Bureau on Further Clarifying the Requirements of Epidemic Prevention for Units Working in Commercial Buildings. Available online: http:/ / www.beijing.gov.cn/zhengce/zhengcefagui/202002/t20200224_1667875.html (accessed on 16 August 2021).

58. World Health Organization. Coronavirus Disease 2019 (COVID-19): Situation Report, 52. Available online: https: / apps.who. int/iris/handle/10665/331476 (accessed on 16 August 2021).

59. Lu, Y.; Wu, J.; Peng, J.; Lu, L. The perceived impact of the Covid-19 epidemic: Evidence from a sample of 4807 SMEs in Sichuan Province, China. Environ. Hazards 2020, 19, 323-340. [CrossRef]

60. Davis, R. Shanghai Disney Resort, Closed in January due to Coronavirus, Set to Partially Reopen Monday. Available online: https://variety.com/2020/biz/news/shanghai-disney-resort-disneyland-reopen-china-coronavirus-1203527299/ (accessed on 15 April 2020).

61. Levin, N.; Kyba, C.C.M.; Zhang, Q.L.; de Miguel, A.S.; Roman, M.O.; Li, X.; Portnov, B.A.; Molthan, A.L.; Jechow, A.; Miller, S.D.; et al. Remote sensing of night lights: A review and an outlook for the future. Remote Sens. Environ. 2020, 237, 111443. [CrossRef]

62. Bustamante-Calabria, M.; Sánchez de Miguel, A.; Martín-Ruiz, S.; Ortiz, J.-L.; Vílchez, J.M.; Pelegrina, A.; García, A.; Zamorano, J.; Bennie, J.; Gaston, K.J. Effects of the COVID-19 Lockdown on Urban Light Emissions: Ground and Satellite Comparison. Remote Sens. 2021, 13, 258. [CrossRef]

63. Jechow, A.; Hölker, F. Evidence that reduced air and road traffic decreased artificial night-time skyglow during COVID-19 lockdown in Berlin, Germany. Remote Sens. 2020, 12, 3412. [CrossRef]

64. Venter, Z.S.; Aunan, K.; Chowdhury, S.; Lelieveld, J. COVID-19 lockdowns cause global air pollution declines. Proc. Natl. Acad. Sci. USA 2020, 117, 18984-18990. [CrossRef]

65. Zhou, M.; Jiang, J.; Langerock, B.; Dils, B.; Sha, M.K.; De Mazière, M. Change of CO Concentration Due to the COVID-19 Lockdown in China Observed by Surface and Satellite Observations. Remote Sens. 2021, 13, 1129. [CrossRef]

66. De Miguel, A.S.; Kyba, C.C.; Zamorano, J.; Gallego, J.; Gaston, K.J. The nature of the diffuse light near cities detected in nighttime satellite imagery. Sci. Rep. 2020, 10, 1-16.

67. Yu, M.Z.; Bambacus, M.; Cervone, G.; Clarke, K.; Duffy, D.; Huang, Q.Y.; Li, J.; Li, W.W.; Li, Z.L.; Liu, Q.; et al. Spatiotemporal event detection: A review. Int. J. Digit. Earth 2020, 13, 1339-1365. [CrossRef] 